\title{
CONTEXTOS Y TRANSICIONES: LA JUSTICIA TRANSICIONAL EN SUDÁFRICA Y COLOMBIA
}

Contexts and transitions: transitional justice in South Africa and Colombia

Daniel E. Flórez Muñoz ${ }^{1}$

Camilo Villareal Ordosgoitia ${ }^{2}$

Recibido: 18 de septiembre 2019 - Aceptado: 10 de diciembre de 2019

\section{RESUMEN}

En la actualidad la justicia transicional recoge el conjunto de estrategias, internacionalmente admitidas para la superación de contextos de alta conflictividad hacia la consolidación de la paz y la democracia. No obstante, la misma ostenta una naturaleza casuística que se alimenta, directamente, de las experiencias exitosas, así como de los importantes estándares, en materia de derechos de víctimas que, con base en dichas experiencias, construyen los organismos internacionales. Resulta de suprema importancia la profundización de un enfoque comparado, al interior de las instancias de comprensión y evaluación de las transiciones políticas a la paz y la democracia. El presente artículo tiene por objetivo presentar algunos elementos determinantes en la comprensión de la experiencia del conflicto y la transición a la paz en los países de Sudáfrica y Colombia, señalando los contextos que sirven para identificar las particularidades de cada una de estas experiencias, así como las posibles lecciones que a la luz de las mismas se pueden identificar.

Palabras clave: Justicia transicional; conflicto armado; apartheid; Colombia; Sudáfrica; Construcción de Paz.

\footnotetext{
' Profesor de Derecho, Universidad de Cartagena. Miembro del Grupo de Investigación en Filosofía del Derecho, Derecho Internacional y Problemas Jurídicos Contemporáneos. Director del Semillero en Derechos Humanos de la Facultad de Derecho y Ciencias Política de la Universidad de Cartagena. Orcid: https://orcid.org/0000-0002-1710-2850 E-mail: daniel.florez@hotmail.es

${ }^{2}$ Abogado, Universidad de Cartagena. Orcid: https://orcid.org/0000-0002-6680-9166 E-mail: cavo_0512@hotmail.com
} 
Daniel E. Flórez Muñoz y Camilo Villareal Ordosgoitia

\section{ABSTRACT}

Currently, transitional justice includes the set of internationally accepted strategies for overcoming highly conflictive contexts towards the consolidation of peace and democracy. Nevertheless, it has a casuistic nature that is directly fed by successful experiences, as well as the important problems regarding victims' rights that international organizations build on various experiences. In this sense, deepening a comparative approach within the instances of understanding and evaluation of political transitions to peace and democracy is of paramount importance. The objective of this article is to present some determining elements in the understanding of the experience of conflict and the transition to peace in the countries of South Africa and Colombia, pointing out the contexts that serve to identify the particularities of each of these experiences as well as the possible lessons that can be identified in light of them.

Keywords: Transitional justice; armed conflict; apartheid; Colombia; South Africa; Peacebuilding.

\section{INTRODUCCIÓN}

Mucho se ha hablado de posconflicto, con todo y sus alcances, a lo largo de los últimos años en Colombia, de lo que nos depara a corto, mediano y largo plazo, y los retos que como sociedad debemos enfrentar, pues supone una recomposición integral de aspectos sociales, económicos y políticos. Sin embargo, en el mundo, el tema del posconflicto no es nuevo, pues varios países ya han pasado por este proceso en miras de buscar la paz en sus territorios. Naturalmente, cada proceso de paz y su respectivo posconflicto, son diferentes entre sí, bien sea que tengamos en cuenta sus antecedentes y orígenes, aspectos sociales, culturales, políticos, económicos, religiosos, e incluso, hasta la posición geográfica del territorio, pero el objetivo es básicamente el mismo: alcanzar la paz.

En la actualidad la justicia transicional recoge el conjunto de estrategias internacionalmente admitidas para la superación de contextos de alta conflictividad hacia la consolidación de la paz y la democracia, no obstante, la misma ostenta una naturaleza casuística que se alimenta directamente de las experiencias exitosas, así como de los importantes estándares en materia de derechos de víctimas que con base en dichas experiencias construyen los organismos internacionales. En ese sentido, es de suprema importancia la profundización de un enfoque comparado al interior de las instancias de comprensión y evaluación de las transiciones políticas a la paz y la democracia. El presente artículo tiene por objetivo presentar algunos elementos determinantes en la comprensión de la experiencia del conflicto y la transición a la paz en los países de Sudáfrica y Colombia, señalando los contextos que sirven para identificar las particularidades de cada una de estas experiencias, así como las posibles lecciones que a la luz de las mismas se pueden identificar. 
La correcta implementación de la metodología de la investigación condiciona directamente la consecución de los objetivos planteados al interior del proceso investigativo. Por tal motivo, la selección de un idóneo enfoque metodológico incide de manera positiva en la calidad de la información recopilada y en el análisis que se haga de ésta (Lafuente \& Marín, 2008: 6). En ese orden de ideas, se adopta un enfoque metodológico de corte cualitativo de tipo documental, al interior del cual, en atención a la profundidad de la investigación, se reconoce su naturaleza tanto descriptiva como pura o fundamental de la misma.

Se acudirá al método descriptivo como estrategia de presentación de lo observado desde las diversas fuentes de información escogidas, este método permite especificar las propiedades, característica y perfiles de un grupo importante de personas, comunidades o cualquier otro fenómeno que sea sometido a análisis. De forma paralela al método descriptivo, se empleará el método analítico con el fin de realizar una descomposición de los elementos diversos o heterogéneos que conforman el fenómeno objeto de estudio o investigación, de tal manera que permita conocer su esencia y particularidades.

Adicionalmente, es necesario, de igual forma, dar una breve explicación de la técnica de investigación a utilizar. En este sentido Maya (2014: 4) resalta la importancia de esta al establecer que comprende un conjunto de procedimientos organizados sistemáticamente que orientan al investigador en la tarea de profundizar el conocimiento y en el planteamiento de nuevas líneas de investigación. Por lo tanto, es necesario aclarar que este artículo está fundamentado principalmente sobre una técnica de investigación cualitativa, en atención al predominio interno de las características de investigación para obtener, aplicar y procesar la información que se obtiene alrededor de la temática de estudio (Rojas, 2011: 278). Por ello se empleará la técnica de investigación documental, especialmente la técnica de análisis de contenido con la finalidad de efectuar deducciones lógicas y justificables concernientes a las fuentes seleccionadas, atendiendo a los criterios de pertinencia, objetividad y autoridad que demanda la investigación (López, 2002: 175).

El presente artículo iniciará con una presentación del concepto de justicia transicional identificando sus principales características y elementos que a la luz de la doctrina especializada se destacan. Seguidamente se abordará el conflicto sudafricano, precisando su cronología y los principales hechos que marcaron su superación. Finalmente abordaremos el caso colombiano precisando las diferentes apuestas que a lo largo de la historia nacional tuvieron lugar en la consecución de la paz y que sirven de antesala a los Acuerdos de la Habana, se presenta en términos generales las principales características del Sistema Integrado de Verdad, Justicia, Reparación y No Repetición para concluir finalmente con algunas lecciones que a la luz de la experiencia sudafricana convendría tener presente en el proceso colombiano. 
Daniel E. Flórez Muñoz y Camilo Villareal Ordosgoitia

\section{Aproximación al concepto de justicia transicional}

Buena parte de la academia comprometida con la superación pacifica de escenarios de abierta confrontación violenta y violaciones sistemáticas de derechos humanos, reconoce la necesidad de asumir estrategias orientadas a la comprensión de las condiciones que en un primer lugar generaron un pasado de abusos a gran escala y junto a éstas la definición de estrategias institucionales, jurídicas y sociales conducentes a una integral superación de las mismas, esta mirada hacia atrás es la condición de posibilidad de un proceso de transición pertinente en relación a las particularidades contextuales que determinaron el surgimiento y mantenimiento del escenario objeto a superar. Lo anterior se adscribe directamente en el espíritu de las palabras de Louis Joinet cuando afirmaría que "para pasar la página, hay que haberla leído antes"; reconociendo de esta forma que asumir que el deber de "recordar los horrores del pasado no deriva de un anclaje malsano en el pasado sino de un esfuerzo deliberado por construir un futuro libre de dichas atrocidades" (Uprimny, et al. 2006: 3), parafraseando a Elie Wiesel (1986) podemos afirmar que la memoria del mal es también un escudo contra el mal mismo.

Este dialogo entre pasado y futuro mediado por el presente es quizá la principal particularidad de los estudios ubicados bajo la etiqueta de "justicia transicional". La espinosa pregunta de qué hacer con las atrocidades del pasado, al tiempo que se siembran las bases para la reconciliación futura, y se persuade a los actores del conflicto para la iniciar la superación del mismo en el presente, supone complejos procesos de armonización entre las exigencias que se elevan desde cada una de las temporalidades, la injusticia padecida en el ayer, la voluntad de los actores en el hoy, y las expectativas de las víctimas, victimarios y sociedad civil en el mañana. Es por esto que la justicia transicional puede ser entendida como un escenario para la disputa abierta en torno al alcance de los derechos de las víctimas, los tipos de beneficios para los actores del conflicto, y por supuesto los horizontes históricos que definen en un primer lugar tanto a los unos como a los otros.

A lo que se apunta a la hora de comprender un proceso de transición es a encontrar en él un balance entre los distintos momentos generacionales, es decir, reconocer en el marco de la transición cómo cada una de las temporalidades compromete desde su propia óptica el proceso de transformación social orientado al restablecimiento de las condiciones políticas y sociales requeridas para la democracia y la reconciliación, pero también estas temporalidades elevan exigencias y garantías tanto jurídicas como éticas, diferenciadas y no en pocos casos contradictorias. Esta situación parece especialmente sintomática en procesos de transición producto de negociaciones políticas, ya que es en esos casos en los que se plantea la necesidad de promover incentivos significativos para que los responsables de crímenes atroces acepten dejar atrás el conflicto y se adhieran a un proceso de desmovilización que asegure la transición (Saffon, 2011: 14). Este tipo de situaciones son 
las que suponen mayores tensiones entre la lógica política de la consecución de la paz y la exigencia jurídica de la garantía de los derechos de las víctimas.

Hacer justicia con el pasado limita las condiciones bajo las cuales proyectamos la reconciliación en el futuro, este tipo de tensiones y dilemas, que solo pueden encontrar su resolución en el marco de los horizontes socio-políticos y capacidades institucionales propias de cada escenario de transición, son los que parecen marcar los principales linderos teóricos de los estudios de la justicia transicional.

Para Rodrigo Uprimny, se encuentra en el corazón mismo de la justicia transicional la relación entre, por una parte, tanto los imperativos jurídicos y éticos de castigar a los responsables de las atrocidades como la satisfacción de los derechos de las víctimas; y por otra, las restricciones derivadas de las realidades políticas propias de los procesos transicionales (Uprimny, 2009: vii). Esta relación genera importantes tensiones, que hacen que el matrimonio entre la paz y la Justicia, no sea en lo absoluto pacifico, sus dilemas a gran escala comprometen directamente no solo la manera en la que dichos procesos son valorados por la opinión pública, sino también los resultados concretos de los mismos y el potencial democratizador de la transición.

Para Rama Mani ${ }^{3}$ el concepto de justicia transicional surge en la década de los años noventa cuando los países que habían sufrido guerras y crisis políticas violentas comenzaron sus transiciones hacia la paz o la democracia, éstos miraron simultáneamente hacia atrás, con el propósito de enfrentar el legado de un pasado brutal y hacia adelante para, a la manera del ave fénix, renacer de sus cenizas (Mani, 2011: 156). Dichos procesos estuvieron marcados por un dilema, el cual acompaña aún hoy los procesos de transición en el mundo entero, consistente en cómo atender las reclamaciones legítimas de justicia presentadas por las víctimas y los sobrevivientes de los abusos horribles, de tal manera que se consiga el delicado balance entre evitar la vuelta al conflicto o una crisis, por un lado, y por otro consolidar una paz duradera basada en la equidad, el respeto y la inclusión, lo que requiere reformas institucionales y cambios sistémicos. Los investigadores dedicados al estudio de la paz llaman al primero de estos fines - ponerles fin a las hostilidades y prevenir la vuelta de la violencia- "paz negativa; al segundo -consolidar la paz mediante reformas estructurales y políticas incluyentes- lo denominan "paz positiva". Por lo tanto, el objetivo y el reto de la justicia transicional se podrían resumir como el logro del equilibrio entre los

\footnotetext{
${ }^{3}$ Phd en Ciencia Política, Universidad de Cambridge. Referente internacional en materia de justicia transicional en especial a la dimensión y alcance del derecho a la reparación en el marco de las transiciones. En la actualidad es investigadora asociada del Centro de Estudios Internacionales de Oxford y es asesora del Centro Global para la Responsabilidad de Proteger. Sus principales obras son: Mani (2009; 2008; 2007; 2006a; 2006b)
} 
requisitos imprescindibles para la paz positiva y la paz negativa, a veces contradictorios entre sí. (Mani, 2011: 158-159)

La justicia transicional desde esta perspectiva no tiene como objetivo o finalidad la de resolver exclusivamente el problema de los torturadores, sino darle solución a un legado de abusos que hereda un contexto democrático (Peña, 2011: 34). Lo anterior implica que la democracia señala unos linderos a este tipo de soluciones negociadas, pero adicional a esto, los procesos que se adelantan para adoptar dichas medidas deben ser en sí mismo democratizadores o ayudar a solidificar la democracia (De Greiff, 2007: 25).

Esta filigrana política, que representa un puro ejercicio de ponderación axiológica, expresa en buena medida la naturaleza -o "corazón", siguiendo la expresión de Uprimny- de la justicia transicional. Se trata de un difícil ejercicio en el que la sociedad debe lidiar con las atrocidades de su pasado, pero con la mirada puesta en un futuro librado de dichos flagelos, todo esto a través de un campo en el que cada vez son menos los aspectos que quedan librados a la deliberación política y pasan a ser entendidos como límites jurídicos a las negociaciones.

\section{Del conflicto a la transición en Sudáfrica}

El Apartheid es uno de los episodios más lamentables en la historia de humanidad. Reprochable desde todo punto de vista. Un sinnúmero de víctimas directas producto de desapariciones, desplazamientos, despojo de tierras, creación de lugares separados por razas, prohibición de derechos democráticos, e incluso, no permitir matrimonios entre blancos y negros. Luego de este doloroso periodo, comenzó un proceso de transición hacia la reconciliación y la paz que comenzó con la abolición de las leyes discriminatorias, y la negociación de una nueva constitución entre el gobierno vigente y los partidos representativos de la población negra que por años fueron silenciados.

Durante esta negociación y etapa de diálogo, surgió la imperante necesidad de escuchar a las víctimas, buscar perdón, reconciliación y paz en la nueva Sudáfrica. Para ello, nació la Comisión de la Verdad y la Reconciliación, como institución encargada no solo de escuchar a las víctimas, sino también de servir como puente entre estas y los victimarios, con facultad para investigar y conceder amnistías, y realizar recomendaciones para evitar la repetición de escenarios de discriminación y violencia. Sin duda, esta Comisión de la Verdad y la Reconciliación jugó un papel fundamental en esta etapa crucial para Sudáfrica, y que se ha convertido además en ejemplo emblemático para otros países que posteriormente han atravesado procesos similares. 


\subsection{Cronología del Apartheid}

Desde el inicio del Apartheid, y su posterior desarrollo en Sudáfrica, ocurren una serie de eventos que merece la pena tener en cuenta:

- 1948: Se institucionalizó el Apartheid con la llegada al gobierno del Partido Nacional como un sistema de segregación racial marcada fundamentalmente por la represión política y el racismo. Se clasificó a la población en cuatro grupos raciales: blancos, mestizos, asiáticos y negros, todos con diferencias sustanciales en lo social, en lo político y en lo económico. Los servicios se brindaban según la raza, siendo superiores los destinados a la población blanca, especialmente los relacionados a la sanidad. La libre circulación también estaba restringida, especialmente para los negros, pues existían zonas exclusivas para los blancos, como escuelas, hospitales, parques, playas, autobuses y hasta sectores residenciales. Para ello, existieron los "homeland" que era territorios delimitados para alojar a la población negra. En lo político, los partidos representativos de la comunidad negra fueron prohibidos, por lo que comenzaron a operar desde la clandestinidad (Vivas et al, 2016: 49-50).

- 1954: El Partido Nacional vuelve a ganar las elecciones presidenciales (con partidos políticos de blancos y electores blancos) de la mano de Johannes Gerhardus, quien agigantó la brecha racial marcando profundas diferencias entre blancos y negros en cuanto a condiciones básicas para la subsistencia como la vivienda, la salud, e incluso la electricidad y el agua. De igual forma, los mestizos y los asiáticos podían tener sus propios negocios y manejar sus asuntos, aunque bajo supervisión de los blancos. Para los negros, lo anterior estaba completamente prohibido, y como si fuese poco, se les convirtió en extranjeros ya que se les eliminó la ciudadanía sudafricana considerándolos una población temporal o transeúnte (Vivas et al, 2016: 50).

- 1961: El país se retira del Commonwealth. Se emitió la Convención Internacional para la Supresión y el Castigo del Crimen del Apartheid, y el Estatuto de Roma definió el apartheid como un crimen contra la humanidad (Boraine, 2007, p. 36). Comenzaba a sentirse la presión y el aislamiento internacional. El Comité Olímpico Internacional excluyó a Sudáfrica permanentemente de los Juegos Olímpicos hasta no eliminar todas las políticas de racismo instauradas.

- 1964: Nelson Mandela es condenado a cadena perpetua.

- 1970: Debido al fuerte aislamiento internacional, Sudáfrica buscó alianzas con otros países en similar situación, de modo que encontró apoyo en Brasil, Chile e Israel, los dos primeros gobernados por dictaduras militares, y el último, no 
reconocido por los árabes, por tal razón también eran rechazados internacionalmente.

\subsection{Etapa de negociaciones y transición a la democracia}

Luego de años de aislamiento internacional, brotes de violencia y crisis económicas, el presidente de la época, Frederick W. De Klerk, da su brazo a torcer y "anunció en 1990 la abolición de las leyes discriminatorias, el levantamiento de las prohibiciones sobre los partidos de oposición y la liberación de Nelson Mandela después de 27 años de prisión" (Boraine, 2007).

El restablecimiento de la democracia implicó que los partidos que de la población negra que durante años operaron en la clandestinidad, regresaran a la vida política.

Así las cosas, para el año 1994 se llevan a cabo elecciones presidenciales, con la participación de la población negra y los partidos políticos representativos de esta población, en las cuales resultó vencedor Nelson Mandela por el CNA (Congreso Nacional Africano).

El fin del apartheid fue el logro de muchos años de resistencia de la población negra sudafricana, y de todos los actores internacionales, incluida la ONU. El reto fundamental que se debía afrontar era buscar una solución de fondo al conflicto sociopolítico, originado por tantos y tantos años de injusticias, donde muchas víctimas reclamaban más que todo verdad en cuanto a las desapariciones, asesinatos y torturas cometidas durante el apartheid. Así pues, "se abren procesos de negociación y se ponen en marcha mecanismos de construcción de una paz duradera por medio de la reconciliación y la restauración de la confianza en el periodo del posconflicto" (Vivas et al, 2016: 53).

\subsection{Comisión de la verdad y la reconciliación en Sudáfrica}

Antes de su creación, en medio de los diálogos de negociación entre el aún gobierno vigente de Frederick W. De Klerk y el Congreso Nacional Africano, en cabeza de Nelson Mandela, surge la gran necesidad de conocer de propia voz de las víctimas, sus pensamientos y lo que esperaban de este proceso, por lo cual se realizó una serie de talleres con colaboradores nacionales e internacionales, hasta recoger todos los testimonios de personas que sufrieron y padecieron durante el apartheid. Se resaltó siempre el gran interés de las víctimas por instruirse, por aprender, por conocer sus derechos, por sugerir y aportar ideas, sin embargo, fue una ardua labor, ya que muchas de las víctimas habían sido desplazadas a lugares remotos, y, además, un gran porcentaje eran analfabetas debido al difícil acceso a la educación para la población negra. El resultado de todos estos talleres y congresos fue 
llevado al Parlamento de Sudáfrica, y así, por medio de ley, fue nombrada la Comisión de la Verdad y la Reconciliación (Boraine, 2007: 35-36).

Esta comisión fue básicamente una institución transitoria de gran alcance, que se encargó de escuchar a unas 22 mil víctimas aproximadamente (Boraine, 2007, p. 35), a través de audiencias públicas, en las que contaban con la oportunidad de enfrentar cara a cara a sus victimarios, desahogar su dolor, y escuchar la verdad, explicaciones, razones, y por supuesto, un perdón. Estas audiencias fueron transmitidas por medios nacionales, como radio y prensa (Boraine, 2007, p. 36).

Al contar con una amplia participación pública en su estructuración, en su mandato y en la selección de las personas que la conformarían, logró gran aceptación y credibilidad entre los sudafricanos. Nelson Mandela contaba con todo el poder para elegir a los miembros de la comisión, al haber ganado las elecciones presidenciales, pero prudentemente optó por nombrar un comité de asesores con el fin de no cometer ningún error. Así las cosas, dicho comité a través de audiencias públicas logró reunir 299 nombres de personas con perfil para conformar la comisión. De esos 299 nombres, el comité seleccionó 25 que fueron presentados al presidente Mandela, quien a su vez seleccionó a los 17 que finalmente conformarían la comisión. Se establecieron cuatro oficinal regionales en todo el territorio sudafricano, y, además, se establecieron tres comités internos en la comisión (Boraine, 2007 , p. 38, 39)

- Comisión sobre Violaciones a los Derechos Humanos: Encargados principalmente de establecer el número de víctimas y de las entrevistas y testimonios con los mismos.

- Comité sobre Amnistía: Las amnistías se concedían de manera individua y condicionada. Los perpetradores debía contar toda la verdad y la totalidad de las conductas cometidas, además de pedir perdón.

- Comisión sobre Reparación y Rehabilitación: Debían establecer la manera en la que serían reparadas y rehabilitadas las víctimas, y de las recomendaciones finales para no repetir eventos futuros de violencia y discriminación.

Eventualmente, la Comisión de la Verdad y la Reconciliación tuvo un gran espectro de poderes de investigación, otorgamiento de amnistías e informe final de gran alcance. También fue de gran utilidad como mecanismo de creación de un registro de violación de derechos humanos, casos de discriminación y represión política (Simpson, 1998). Lógicamente, no todas las víctimas que ofrecieron sus testimonios y contaron sus historias ante la comisión fueron el total de ellas, también muchas otras personas optaron por no 
Daniel E. Flórez Muñoz y Camilo Villareal Ordosgoitia

asistir, ni contar lo que les había sucedido, y eso fue respetado, no se obligó a nadie a hacer nada en contra de su voluntad, pero también se les brindó ayuda y acompañamiento, pues en el fondo, todas las víctimas eran personas angustiadas, con muchos temores, con sentimientos de incertidumbre hacia el cambio, y la idea era respetar el proceso de dolor de cada uno, comprender a las víctimas no como una masa uniforme con igualdad de necesidades, sentimientos y expectativas, sino como universos particulares e individuales que a pesar de tanto sufrimiento, las ganas de comenzar una nueva vida estaban latentes en cada uno de ellos.

El eje principal de esta comisión fueron las víctimas. Siempre se les hizo énfasis en el tema de la reconciliación. En ese sentido, el comienzo de todo este proceso fue positivo, pues se logró pasar de vivir excluidos como raza a compartir lugares en común, todos, sin excepción, y aceptarse los unos con los otros. Sin embargo, el tema de la amnistía fue un tanto espinoso y difícil de abordar. La propuesta de amnistías no nació de la Comisión de la Verdad y la Reconciliación, de hecho, fue producto de las negociaciones de la nueva constitución y el fin del conflicto. El Partido Nacional pretendía establecer un marco legal que facilitara la amnistía total para los perpetradores (Boraine, 2007, p. 37).

Las víctimas no recibieron este tema con agrado, muchos sintieron que jugaban con su dolor y sufrimiento, y pensaron que todo sería un teatro para que algunos pocos lograran acceder al poder, pero fue Nelson Mandela con su ejemplo quien logró un gran cambio en la mentalidad de las víctimas. Él mismo insistió en la necesidad de la reconciliación desde la verdad y el perdón, del perdón a cambio de verdad, ya que solo así se lograría la unidad en los sudafricanos, el fortalecimiento de un sistema democrático incluyente, y, sobre todo, respetuoso de los derechos humanos. Fue así como las víctimas comprendieron en gran medida que, si Nelson Mandela, después de haber soportado 27 años de prisión, hacia un llamado al perdón, a la unidad y a la verdad, ellos también podían dar el paso y responder a ese llamado de cambio y transición hacia la paz y hacia una nueva Sudáfrica (Boraine, 2007, p. 37).

Por lo tanto, la Comisión de la Verdad y la Reconciliación fue implacable en con respecto a la amnistía, ya que esta solo era concedida de manera individual y condicionada. Para ello, los victimarios, en audiencia pública, debían contar toda la verdad, con detalles, y pedir perdón a sus víctimas. Si se descubría que omitían detalles, no pedían perdón, o simplemente optaban por no contar la verdad, era procesados por crímenes de guerra. Es importante aclarar que los crímenes cometidos por los perpetradores debían tener un fundamento o motivación política (Boraine, 2007, p. 39).

En cuanto al informe final de la Comisión de la Verdad y la Reconciliación, se resalta lo siguiente: 
En el informe final, presentado el 29 de octubre de 1998 al presidente, la Comisión estableció que el apartheid fue un crimen contra la humanidad y reconoció como una "guerra justa" la resistencia armada contra el apartheid. No obstante, aclaró que así fuera un crimen contra la humanidad no significaba que los actos realizados para destruirlo fueran legales, morales y aceptables. A pesar del trabajo de la Comisión y del proceso de amnistía, según el informe final "la comunidad blanca casi siempre apareció o indiferente $\mathrm{u}$ hostil al trabajo de la Comisión. Con raras excepciones individuales, las respuestas del Estado anterior, de sus líderes, instituciones y de los órganos más destacados de la sociedad civil de ese periodo fue la de eludir, tapar y confundir”. (Boraine, 2007, p. 39)

\subsection{Sudáfrica en la actualidad}

Pero, ¿cómo debería ser la Sudáfrica después del apartheid?, ¿cómo es en realidad? ¿realmente ha cambiado Sudáfrica con el fin del apartheid, o todo sigue igual? Son interrogantes a los que sus respuestas varían según la perspectiva desde la que se analice. Por ejemplo, en materia de educación, durante el apartheid, hasta los libros de las escuelas eran diferentes según la raza de los niños: "Los de los blancos eran de tapa dura y tenían ilustraciones a color; los de los negros, de papel endeble y en gris" (Agejas \& Panadero, 2013). De hecho, los modelos de educación no eran iguales para un niño blanco y para un niño negro, y sus escuelas eran separadas. Con el fin del apartheid, las escuelas se volvieron multirraciales, la educación es igualitaria, el afrikáans dejó de ser obligatorio, y se enseñan lenguas maternas.

Ahora bien, en términos de vivienda, la situación no es la mejor. Luego del apartheid, lejos de unificar los sectores de blancos y negros en las zonas urbanas y rurales, Nelson Mandela mejoró las condiciones de vivienda y servicios básicos de la población negra, pero, ahí mismo, en sus asentamientos. Es decir, las ciudades seguían (y algunas aún siguen) divididas, los negros, con mejores condiciones, pero aún marginados en los sectores asignados desde el apartheid. Incluso, después del apartheid, muchas personas marginadas en zonas rurales, decidieron marcharse a las grandes ciudades en busca de mejores oportunidades, y se asentaron en nuevos suburbios. Muchas de esas personas, aún continúan con carencias en condiciones dignas de vivienda. Si bien, ya no existen zonas restringidas para los negros, ni zonas exclusivas para los blancos, lamentablemente, las barreras geográficas del apartheid persisten estructuralmente en muchas ciudades. Es muy extraño encontrar a una persona blanca, pobre y viviendo en una zona habitada mayoritariamente por negros. Es más común encontrar a una persona negra, viviendo con lujos en una zona habitada en su mayoría por personas blancas.

Esa es la otra cara de la moneda: ¿cómo logra una persona negra, mestiza o asiática ser millonaria en Sudáfrica?: 
El total de negros, asiáticos y mestizos millonarios en Sudáfrica se amplió de los 6200 que había en 2007 a 17.300 en 2015, de acuerdo con New World Wealth, una empresa de consultoría con sede en Johannesburgo. Lo que muchas de estas personas tienen en común son vínculos lucrativos con el gobierno. (Goodman, 2017)

Por supuesto, hay sectores en las grandes urbes, como Johannesburgo, Ciudad del Cabo, Pretoria, Durban y Port Elizabeth, donde es bastante usual encontrar sectores habitados por personas de todas las razas, con diferentes religiones y culturas, blancos, negros, asiáticos, cristianos, protestantes, hindúes, conviviendo en total armonía. Incluso, en estos sectores de estas ciudades, ya es completamente normal ver familias multirraciales (teniendo en cuenta que durante el apartheid los matrimonios entre blancos y negros estaban prohibidos). La generación de jóvenes que crecieron con nuevas oportunidades y con posibilidades de educarse, tienen otra perspectiva en comparación con generaciones anteriores, como sus padres o abuelos, que aún suelen cargar heridas por todo lo ocurrido.

Lejos de ser un país perfecto, y con muchos retos que superar, Sudáfrica le demostró al resto del mundo que es posible avanzar, perdonar, insistir en el diálogo, en humanizar el conflicto. No es Sudáfrica el paraíso terrenal, nuevamente, no es perfecto, pero, ¿estaría en las mismas condiciones en las que se encuentra actualmente si no se hubiese terminado el apartheid? ¿La situación actual de Sudáfrica sería la misma si se hubiese insistido en una guerra civil? Evidentemente no.

El fin del apartheid fue el inicio de un largo proceso de reconstrucción política, económica y social que aún no ha terminado.

\section{3. la experiencia de la justicia transicional en Colombia}

Para analizar el conflicto colombiano es necesario comprender el contexto político y social que dio origen a uno de los peores episodios, extendido por más de medio siglo, en la historia de Colombia.

\subsection{Cronología del conflicto en Colombia}

De manera cronológica, se podría establecer una tentativa cronología del conflicto armado colombiano a partir de los siguientes hechos:

- 1948: No es el inicio del conflicto en Colombia, pero, con el asesinato de Jorge Eliécer Gaitán, se marca un antes y un después en el periodo conocido como "La Violencia", caracterizado por la confrontación bipartidista entre liberales y conservadores. Fue una época sangrienta y llena de profundas desigualdades 
sociales. Se considera la antesala, como contexto en general, al nacimiento de las FARC, y con ello, del conflicto.

- 1964: El período de "La Violencia", dejó un panorama desolador de muerte y desplazamientos. Grupos de campesinos desplazados de corriente liberal, que más tarde adoptaron la ideología comunista, se adentraron en la cordillera central, en Marquetalia (Tolima). "A la cabeza de este grupo estaba Manuel Marulanda Vélez, "Tirofijo", un combatiente formado en las guerrillas liberales de inicios de los 50, quien se convertiría en el primer jefe de las FARC" (Cosoy, 2016). A mediados de ese mismo año, este grupo de campesinos armados es atacado por fuerzas estatales, lo que los obliga a dispersarse, pues fueron derrotados.

- 1966: Luego de dicha derrota, al reagruparse nuevamente, se forma un grupo guerrillero llamado "Bloque Sur", liderado nuevamente por Manuel Marulanda junta a Jacobo Arenas, pero eventualmente se establecen con un nuevo nombre: Fuerzas Armadas Revolucionarias de Colombia ${ }^{4}$.

- Finales de la década de los 60, década de los 70: Surgen otros grupos guerrilleros como el Ejército de Liberación Nacional (ELN), Ejército Popular de Liberación (EPL), y el M-19. Actualmente persiste la lucha contra el ELN.

- Década de los 80: Con el nacimiento de los grupos paramilitares y la influencia del narcotráfico, se profundiza la violencia en el conflicto colombiano.

- Década de los 90: Nueva Constitución Política en 1991. Fortalecimiento de los grupos paramilitares y la guerrilla de las FARC.

- 2000 y años subsiguientes: Para el año 2000, las FARC ya contaban con unos 20.000 hombres en armas (Cosoy, 2016), y comienza una época sumamente violenta en Colombia, con métodos de guerra sangrientos: masacres, principalmente por grupos paramilitares, y secuestros, en manos de las FARC. Todo ello llevó a una violación sistemática de los derechos humanos, principalmente contra la población civil.

\subsection{Acuerdos de la Habana}

Para llegar al punto de los Acuerdos de la Habana, es necesario mencionar todos los intentos anteriores que hubo en miras de alcanzar la paz entre las FARC y el gobierno.

- 1974: Durante el gobierno de Alfonso López Michelsen, el ELN tuvo la intención de rendirse a cambio de una amnistía, sin embargo, al intentar establecer los diálogos, el ELN no se presentó al lugar por "falta de garantías".

\footnotetext{
${ }^{4}$ Pero las FARC no fueron solo un producto de la historia colombiana, sino también de lo que ocurría en el mundo: surgen en el marco de las luchas de liberación latinoamericanas, alimentadas por la tensión EE.UU.-Unión Soviética de la Guerra Fría. (Cosoy, 2016)
} 
- 1984: El presidente de la época, Belisario Betancur Cuartas, insistió en diálogos con las FARC, EPL, ELN y M-19. Aunque se lograron adelantar ciertos puntos, todo terminó con la toma al Palacio de Justicia, aduciendo incumplimientos por parte del gobierno.

- 1986: Virgilio Barco logró acuerdos de paz con el ELP y el M-19. Con las FARC el intento fue infructuoso. "El 8 de marzo de 1990 los combatientes del M-19 entregaron armas bajo las órdenes de su líder Carlos Pizarro. Luego de eso se convirtieron en un grupo político denominado Alianza Democrática M19”. (Fajardo, 2016)

- 1990: César Gaviria inició diálogos de paz con las FARC, ELP y ELN. Los mayores acercamientos se lograron con el ELP, sin embargo, todo finalizó con el secuestro y muerte del exministro Angelino Durán en manos del ELP.

- 1994: Con mediación de Alemania, Ernesto Samper inició diálogos con el ELN. "En los diálogos se consiguió un preacuerdo de cese al fuego. Luego de la muerte de Manuel 'El Cura' Pérez, máximo comandante del ELN, se acabó el proceso". (Fajardo, 2016)

- 1998: Procesos fallidos tanto con las FARC como con el ELN durante el gobierno de Andrés Pastrana. En el caso las FARC, con el evento del despeje del Caguán y "la silla vacía", terminó todo intento de diálogo. Con el ELN, se intentó otra zona de despeje, pero el grupo guerrillero abandonó las conversaciones aduciendo incumplimiento del gobierno.

- 2005: Entre el año 2005 y 2007, bajo el gobierno de Álvaro Uribe, se llevaron a cabo rondas exploratorias con el ELN en La Habana, Cuba. Los intentos llegaron a su fin sin éxito en 2008.

Así las cosas, desde el año 2012, el gobierno, en cabeza de Juan Manuel Santos, y las FARC comenzaron conversaciones sobre un acuerdo de paz, unos puntos mínimos como partida. Con la mediación de Cuba y Noruega, se dio inicio al diálogo en La Habana.

Los puntos claves a tratar en estas negociaciones eran una política de desarrollo agrario integral, la participación política, la solución al problema del narcotráfico, los derechos de las víctimas, la terminación del conflicto y mecanismo de refrendación de los acuerdos.

Fueron cuatro años de muchas expectativas, escepticismo e incertidumbre, no obstante, con la negociación exitosa del último de los puntos, en agosto de 2016, se dio fin a la etapa de negociación. El 26 de septiembre del año en mención, se firma el acuerdo entre las FARC y el gobierno de Colombia, en cabeza de Juan Manuel Santos. Presidentes de la región, y demás representantes de la comunidad internacional, estuvieron presentes en la firma del 
acuerdo. El verdadero reto sería entonces la refrendación del acuerdo por parte de la población colombiana. Fue así como el 2 de octubre de 2016 se lleva a cabo un plebiscito para saber si el pueblo aprobaba o rechazaba lo acordado. Los resultados, según datos de la Registraduría Nacional del Estado Civil (2016) revelan que el NO obtuvo 6.431.376 votos válidos, equivalentes al 51.21\%, mientras que el SÍ obtuvo 6.377 .482 votos válidos, equivalentes al $49.78 \%$. Dicho resultado, llevó a replantear ciertos puntos con los sectores del NO, y con la inclusión de algunos nuevos puntos, se firmó el nuevo acuerdo, y definitivo, el 24 de noviembre de 2016 en Bogotá.

Actualmente, con la implementación y la etapa post-acuerdos, Colombia enfrenta varios retos, entre ellos, mantener una voluntad política en pro a la paz, involucrar a los demás actores armados al margen de la ley en diálogos de paz, para que así sea completa y definitiva; y también, trabajar en la trasformación de la cultura:

Tras décadas de violencia, es necesario abordar la desconfianza, el miedo y el odio arraigados. La re-humanización del 'otro' involucra no sólo a los combatientes sino a la sociedad en general. Será difícil que Colombia avance mientras no se reconozca la diversidad de perspectivas dentro de la sociedad como un valor y no como un problema.

El proceso post-acuerdo será casi tan difícil como el de las negociaciones de paz. Las dificultades son enormes. Pero en un momento de conflictos exacerbados y crisis humanitarias en otras partes del mundo, Colombia se está convirtiendo en un referente para la identificación de soluciones políticas a conflicto aparentemente irresolubles. (Conciliation Resources, s.f.)

\subsection{Sistema integral de verdad, justicia, reparación y no repetición}

Es un sistema compuesto por diferentes mecanismos judiciales y extra judiciales que se pondrán en marcha de manera coordinada con el fin de lograr la mayor satisfacción posible de los derechos de las víctimas, asegurar la rendición de cuentas por lo ocurrido, garantizar la seguridad jurídica de quienes participen en el Sistema Integral y contribuir a garantizar la convivencia, la reconciliación y la no repetición del conflicto y así asegurar la transición del conflicto armado a la paz. El SIVJRR cuenta con los siguientes cinco mecanismos, a saber:

- Comisión para el Esclarecimiento de la Verdad, la Convivencia y la No Repetición.

- Unidad especial para la búsqueda de personas dadas por desaparecidas en el contexto y en razón del conflicto armado.

- Jurisdicción Especial para la Paz.

- Medidas de reparación integral para la construcción de la paz. 
Daniel E. Flórez Muñoz y Camilo Villareal Ordosgoitia

- Garantías de No Repetición.

Las víctimas del conflicto siempre han sido el eje central de todas los diálogos, conversaciones y acuerdos, pues son ellas quienes han sufrido los horrores de la guerra. Es por eso que el SIVJRR, predica de su integralidad, en el sentido de que busca satisfacer plenamente las necesidades de las víctimas, que no sean revictimizadas, y puedan cerrar de una vez por todas los sufrimientos causados por la violencia que tango daño le ha hecho a nuestro país. Son 8.679.002 de víctimas (Registro Único de Víctimas, 2018), 8.679.002 de razones para seguir luchando por la paz que tanto esfuerzo nos ha costado. Es nuestro deber histórico y moral como sociedad.

\section{Conclusión: Perspectiva comparada entre Colombia y Sudáfrica}

Aunque ciertamente se podría pensar que Colombia y Sudáfrica tiene poco que ver, ya sea por su gran distancia geográfica, diferencia de idioma, o de acercamientos históricos y culturales entre sí, resulta interesante destacar que aun cuando cronológica, social, política y culturalmente sus conflictos son poco similares, la violencia y la desigualdad sí ha tocado las puertas de ambos países.

Es por eso que, debido a los sufrimientos compartidos, no se escatiman esfuerzos a la hora de colaborarse mutuamente. A muchos les causará sorpresa quizá saber que, en alguna oportunidad, se pudo contar con Nelson Mandela y Desmond Tutu en un eventual proceso de paz en Colombia. Sí. Fue en el año 2005, durante el Simposio Internacional para Justicia Restaurativa y Paz, llevado a cabo en la ciudad de Cali. Se contó con la presencia de Desmond Tutu en compañía de una delegación del gobierno sudafricano, varios expertos en conflictos y procesos de paz en el mundo, y una intervención virtual del mismísimo Nelson Mandela. Desmond Tutu propuso abiertamente a Sudáfrica como sede para iniciar diálogos entre la guerrilla de las FARC y el gobierno colombiano, a lo que el presidente de aquella época, Álvaro Uribe Vélez, contestó: "Me la pone muy difícil. Me preocupa que salgan del país los líderes de la guerrilla y que los demás queden aquí asesinando, poniendo minas antipersonales y secuestrando" (Blog de Banderas, 2012). Varios expertos siguieron insistiendo, Nelson Mandela intervino desde Sudáfrica, y al parecer, Álvaro Uribe Vélez dio señales de dar su brazo a torcer: dio a entender que su comisionado de paz, Luis Carlos Restrepo, comenzaría a gestionar todo el asunto.

Pero fue una victoria que nunca se concretó. Después de la conferencia con el Arzobispo Tutu, Uribe nunca retomó el tema con el gobierno sudafricano y la propuesta de tener a Mandela como mediador se quedó únicamente en palabras (Blog de Banderas, 2012) 
La primera y más grande lección que nos deja Sudáfrica es la del perdón. No fue sencillo dar este paso para la población negra, marginada y discriminada de Sudáfrica, pero sí necesario. Y Nelson Mandela fue el primero en dar el ejemplo: perdonar a sus adversarios, luego de permanecer privado de la libertad por tantos años y separado de su familia. Eso tocó la fibra del pueblo sudafricano. Muchas personas, más que añorar ver a sus perpetradores pasar sus últimos días en una prisión, lo que más anhelaban era saber la verdad, escuchar de viva voz de sus victimarios los hechos, conocer las razones, y un perdón.

La segunda gran lección de Sudáfrica es la educación. En palabras de Nelson Mandela: "la educación es el arma más poderosa que puedes usar para cambiar el mundo”. Y ese fue el primer gran paso en Sudáfrica, inicialmente desde la Comisión de la Verdad y la Reconciliación, educar a la población, llegando a cada habitante y empoderándolo desde su nivel de entendimiento, pues existía mucho analfabetismo en la población negra. Pero no se trataba solo de conocimientos intelectuales, sino también de nutrir el catálogo axiológico en cada individuo, trabajar desde el perdón y construir un nuevo país.

He ahí el papel que nos corresponde asumir como sociedad, desde las instituciones hasta la academia. Instruir, educar, ilustrar, empoderar y hacer partícipes a todos los sectores sociales en todo este proceso, como líderes, como veedores, como activistas. Que los criterios racionales sean la base fundamental para fomentar el diálogo, y que los aportes y las ideas permitan enriquecernos como sociedad. Crear espacios para fomentar la crítica y el debate, donde todos seamos escuchados y donde podamos resaltar todos los valores propios de una democracia.

En cuanto a la verdad como valor fundamental, es necesario que, tal como en Sudáfrica, en Colombia se haga masivo y dominio público todas las audiencias y confesiones que los victimarios puedan hacer. La verdad es el primer paso para que las víctimas puedan cerrar ese ciclo de dolor y avanzar. Es importante el acompañamiento tanto del Estado como de la sociedad, en el apoyo a las víctimas, en humanizar el conflicto y entender la postura del otro.

La justicia es el mayor desafío, porque es allí donde se debe comprender la dimensión y alcances de la justicia transicional. Enfrentarse a la dicotomía de víctimas y victimarios, verdad o silencio, justicia o impunidad, amnistía o penas ejemplares, es trazar un sendero que efectivamente nos llevaría a dimensionar el sacrificio que implicaría lograr la paz. Comprender pues, que la justicia transicional no es una fórmula mágica o perfecta para acabar de raíz y de forma definitiva un conflicto, sino, entenderla como un proceso de matices donde se debe buscar un equilibrio lo más benevolente posible para las partes, de 
Daniel E. Flórez Muñoz y Camilo Villareal Ordosgoitia

construcción a largo plazo, donde se vean involucrados todos los sectores sociales, y que pueda ser sostenible con el paso del tiempo. La justicia transicional no va hacia los extremos, no es impunidad, ni es castigo: es equilibrio.

De ahí, que la reparación a las víctimas deba ser integral. No solo se trata de restablecer sus condiciones de vida tal como estaban antes de convertirse en víctimas, se trata también de mejorarlas. Y no es solo el apoyo y la ayuda material. Tal vez para muchos de poco o nada sirve regresar a sus casas o sus tierras si ya no estará algún miembro de su familia, o la familia entera. Nada reparará esa ausencia y ese dolor. Es por eso también que la ayuda psicológica y social es fundamental para la reparación integral. Brindar oportunidades de empleo, de educación, generar en las víctimas esa motivación y ganas de superarse. Pero también es necesario una sociedad más justa, más abierta al perdón, al diálogo, a la solidaridad. Una sociedad que pueda recibir con los brazos abiertos tanto a las víctimas como a los desmovilizados. Una sociedad sin prejuicios, sin odios, sin rencores. Tal vez suene utópico, pero nunca habrá peor batalla que aquella que no se da hasta el final. Como diría Desmond Tutu: "Perdona a los otros, no porque merezcan ser perdonados, sino porque tú te mereces la paz".

\section{REFERENCIAS BIBLIOGRÁFICAS}

Agejas, M. J. \& Panadero R. (2013). ¿Cómo es la Sudáfrica de 2013 ?

Blog de Banderas. (2012). Álvaro Uribe: el hombre que ignoró a Nelson Mandela y Desmond Tutu. https://blogdebanderas.com/2012/08/23/alvaro-uribe-el-hombre-queignoro-a-nelson-mandela-y-desmond-tutu/

Boraine, A. (2007). Audiencias públicas, claves en Sudáfrica En: Del dolor a la verdad y a la reconciliación. Hechos del Callejón, Ed Especial, No. 21. Bogotá, Colombia.

Centro Internacional Para La Justicia Transicional. (2009). ¿Qué es la justicia transicional? Nueva York, USA: ICTJ. Recuperado de: https://www.ictj.org/es/que-es-la-justicia$\underline{\text { transicional }}$

Conciliation Resources. Working together for peace. (s.f.) Historia: el conflicto colombiano. United Kingdom: Conciliation Resources. Recuperado de. http://148.251.69.135/es/where-we-work/am\%C3\%A9rica-latina/historia-el-conflictocolombiano 
Cosoy, N. (2016, 24 de agosto). ¿Por qué empezó y qué pasó en la guerra de más de 50 años que desangró a Colombia? BBC News. Recuperado de https://www.bbc.com/mundo/noticias-america-latina-37181413

Fajardo, E. (2016). Los múltiples intentos de paz en Colombia. Bogotá, Colombia: El Heraldo, 26 de agosto de 2016. https://www.elheraldo.co/politica/los-multiples-intentosde-paz-en-colombia-280676

Goodman, P. (2017), Lo que queda del 'apartheid' en Sudáfrica. The New York Times, 2 de noviembre de $2017 . \quad$ Nueva York. https://www.nytimes.com/es/2017/11/02/espanol/apartheid-sudafrica-nelson$\underline{\text { mandela.html }}$

Kalach Torres, Gina María (2016). Las comisiones de la verdad en Colombia. Revista Jurídica Mario Alario D'Filippo, Vol 8, número 16: 106-124. DOI: https://doi.org/10.32997/2256-2796-vol.8-num.16-2016-1534

Registraduría Nacional del Estado Civil. (2016). Plebiscito 2 de octubre de 2016. Bogotá, Colombia: República de Colombia. https://elecciones.registraduria.gov.co/pre_plebis_2016/99PL/DPLZZZZZZZZZZZZZZZ ZZ L1.htm

Guevara Flórez, V. y Castañeda Ramírez, K. (2018) Evolución del estado colombiano y su camino hacia la paz. Revista Jurídica Mario Alario D'Filippo, Vol. 10, Número 20: 120131. DOI: https://doi.org/10.32997/2256-2796-vol.10-num.20-2018-2151

Registro Único de Víctimas (RUV). (2018). Reporte General. Junio de 2018

Simpson, G. (1998). A Brief Evaluation of South Africa's Truth and Reconciliation Commission: Some lessons for societies in transition. Centre for the Study of Violence and Reconciliation.

Viguri Perea, A. y Chiara Marullo, M (2016) La protección legal del medio ambiente: desarrollo sostenible y acciones colectivas. Revista Jurídica Mario Alario D'Filippo, Vol. 8, Número 16: 135- 158.DOI: https://doi.org/10.32997/2256-2796-vol.8-num.16-20161536

Vivas, T. (2006). Derechos humanos, paz y posconflicto en Colombia. Revista Colección Jus Publico, No. 9. Bogotá, Colombia. Universidad Católica de Colombia. 